\title{
Presence of Psychoactive Substances in Toxicological Examination of Children and Adolescents Victims of Violent Deaths in Sao Paulo: 2014-2016
}

ISSN: 2578-0042

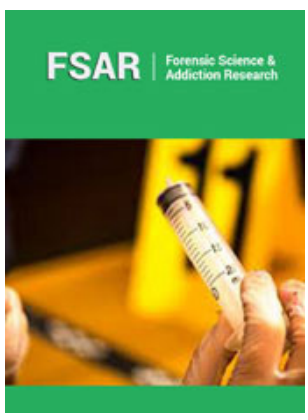

*Corresponding author: Ivan Dieb Miziara, Associate Professor-Head of the Department of Legal Medicine, Ethics and Social Medicine, Sao Paulo University (USP), Rua Teodoro Sampaio, 352-22. São Paulo, Brazil

Submission: 侮 August 28, 2021

Published: 毕October 18, 2021

Volume 5 - Issue 4

How to cite this article: Emílio Zuolo Ferro, Carmen Silvia Molleis Galego Miziara, Ivan Dieb Miziara. Presence of Psychoactive Substances in Toxicological Examination of Children and Adolescents Victims of Violent Deaths in Sao Paulo: 2014-2016. Forensic Sci Add Res. 5(4) FSAR. 000622. 2021

DOI: 10.31031/FSAR.2021.05.000622

Copyright@ Ivan Dieb Miziara, This article is distributed under the terms of the Creative Commons Attribution 4.0 International License, which permits unrestricted use and redistribution provided that the original author and source are credited.

\section{Emílio Zuolo Ferro ${ }^{1}$, Carmen Silvia Molleis Galego Miziara ${ }^{2}$ and Ivan Dieb Miziara $^{3 *}$}

${ }^{1}$ Preceptor of the Department of Legal Medicine, Ethics and Social Medicine, Sao Paulo University Faculty of Medicine, Brazil

${ }^{2}$ Assistant Professor-Department of Legal Medicine and Bioethics-Faculty of Medicine of ABC (Santo André-Brazil), Brazil

${ }^{3}$ Associate Professor-Head of the Department of Legal Medicine, Ethics and Social MedicineSao Paulo University Faculty of Medicine, Brazil

\begin{abstract}
The growing use of both licit and illicit drugs by children and adolescents raises concerns on the part of society as a whole. This is because the health system is overloaded with several avoidable hospitalizations, resulting in several years of life lost in this age group, or for demanding new public health policies to combat the sale and trafficking of these drugs. The present study evaluated 47 cases of deaths due to external causes that were referred to the IML of the state of São Paulo between the years of 2014 and 2016 and analyzed the concomitance of these cases with the positivity of the toxicological test, in order to establish a relationship between the deaths and drugs most frequently encountered. The selected group consisted of $08(17.02 \%)$ women and $39(82.98 \%)$ men. The substances identified in the female group were ethyl alcohol (two cases-25\%); trichloroethylene (two cases-25\%); carbon monoxide (one case-12.5\%); trichloroethylene and chloroform (one case-12.5\%); cocaine and carbamate (one case$12.5 \%$ ); and tricyclic antidepressant (one case-12.5\%). Thirty-nine toxicological tests of male victims were evaluated, of which alcohol alone was present in 20 tests, representing a rate of 51.28\%, in a blood concentration ranging from 0.5 to $4.4 \mathrm{~g} / \mathrm{L}$. It was concluded that alcohol is the most commonly found substance, but trichloroethylene also has an important role.
\end{abstract}

Keywords: Cause of death; Violence; Child; Adolescent; Substance-related; Disorders; Substance abuse detection

\section{Introduction}

According to the Statute of Children and Adolescents (ECA) [1], children and adolescents are people up to 12 and 18 years old, respectively, and represent $32.99 \%$ of the total population of Brazil, according to a census carried out by the Brazilian Institute of Geography and Statistics (IBGE), in 2010 [2]. For both sexes, life expectancy in Brazil went from 45.5 years to 75.5 years, an increase of 30 years from 1945 to 2015. In addition, all ages have benefited from the decrease in mortality levels, especially the younger generations, in which the most significant increases in life expectancy are observed [2]. In the child population of children and adolescents in the State of São Paulo, deaths from external causes totaled 2,312 occurrences, representing $9.33 \%$ of the total of 24,764 deaths in 2015 [3]. Traffic accidents are the leading causes of these fatal outcomes, some of them related to the recent use of alcohol or other drugs [4]. In addition, the use of alcohol by victims under 18 years of age was the most associated with death compared to the consumption of all illicit psychoactive 
substances together [5]. The World Health Organization (WHO) defined drug addiction or drug abuse "as a state of periodic or chronic intoxication, harmful to the individual or society, produced by the repeated use of a natural or synthetic drug." By "toxic" or "drug," it is understood as an extensive group of natural, synthetic, or semi-synthetic substances that can cause tolerance, dependence, and withdrawal crisis [5].

Men's abuse of psychotropic substances has been reported for thousands of years, and alcohol use has been described for at least six thousand years. In the past, these substances were found in nature. Nowadays, more sophisticated means for the production of drugs have been developed with the advance of the pharmaceutical technique [6]. A national survey on the use of psychotropic drugs among elementary and high school students in 27 Brazilian capitals, carried out in 2010, showed that in the State of São Paulo, among 4,073 students interviewed, 41.7\% reported alcohol use and $7.8 \%$ tobacco use [7]. The same study shows that consumption of alcohol begins from childhood to adolescence [7]. These authors relate that a survey conducted in the United States shows that around three million children and adolescents consume tobacco and alcohol; about $50 \%$ of students drink alcohol at least once a month [7]. Another study showed that one in four children and adolescents aged 18 years live together to alcohol abuse in the family environment [8].

Besides, research carried out with adolescents in Latin America, through the application of anonymous and selfadministered questionnaires, showed that alcohol was the most consumed psychoactive substance, with the highest rates in males [9]. However, regarding the gender of the participants, female alcoholism is not faithfully publicized, being more frequent than we can imagine [10]. Due to the increased incidence/prevalence of early and abusive use of drugs by children and adolescents, it is necessary to identify which substance is most frequently related to death in this age group. A simple toxicological exam fulfills this task, being carried out in all cases of the end of children and adolescents that arrive at the Medicolegal Institute in the city of São Paulo. So, our study aims to identify some association between deaths of children and adolescents from external causes and the use of illegal substances. Once established, it will be of paramount importance in terms of public health, guiding public policies to prevent alcohol consumption and other drugs by children and adolescents.

\section{Material and Method}

The Ethics Committee approved this study for Analysis of Research Projects - CAPPesq-University of São Paulo. CAAE 79416717.3.0000.0065. Opinion Number:2,370,930. Due to the Instituto Medico Legal norms, data referring to autopsies can only be used for research purposes, five years after the victims' death. Thus, we made a descriptive, cross-sectional documentary study at the Department of Legal Medicine, Medical Ethics, Social and Labor Medicine at the University of São Paulo, using information obtained from the Medicolegal Institute of the State of Sao Paulo database. In addition, we analyzed only the autopsy reports of children and adolescents age from 10 to 18 years of age, carried out between 2014 to 2016, with positive toxicological examination for some drugs. The toxicological analysis was made in the laboratory of the Medicolegal Institute using $10 \mathrm{ml}$ of blood collected through the right cardiac chamber.

\section{Result}

We evaluated one hundred forty-three (143) autopsy reports of children and adolescents between 10 and 18 years of age in 2015. The purpose of the study was to analyze only the cases of positive toxicological tests to determine the cause of death. Thus, 96 patients were excluded because their toxicological examination was negative. Therefore, 47 reports were evaluated. The selected group consisted of 08 (17.02\%) women and 39 (82.98\%) men, with a mean age of 16.55 years. The mean age for men was 16.51 years, and the mean age for women was 16.9 , with no statistical difference between them. The substances identified in the female group were ethyl alcohol (two cases-25\%); trichloroethylene (two cases-25\%); carbon monoxide (one case-12.5\%); trichloroethylene and chloroform (one case-12.5\%); cocaine and carbamate (one case-12.5\%); and tricyclic antidepressant (one case-12.5\%). Thirty-nine toxicological tests of male victims were evaluated, of which alcohol alone was present in 20 tests, representing a rate of $51.28 \%$, in a blood concentration ranging from 0.5 to $4.4 \mathrm{~g} / \mathrm{L}$. In three reports, ethyl alcohol was accompanied by other substances (trichloroethylene, cocaine, carbon monoxide). Trichloroethylene was detected in 10 tests, in which the drug was in association with other substances in seven (chloroform, marijuana, ethyl alcohol, cocaine). In addition, we found one positive poisoning case caused by aldicarb (a type of carbamate) and one case positive for diazepam. Thus, three substances appear in two cases: one for trichloroethylene, ethyl alcohol, and cocaine and the other for trichloroethylene, phenytoin, and cocaine. We call for attention to some aspects of our case series: the incidence of positive cases for the use of trichloroethylene associated with chloroform. This mixture is known in Brazil as "loló" and is used in inhaled form. Trichloroethylene was also involved in four cases whose cause of death was pulmonary edema. It is worth remembering that pulmonary edema usually occurs due to heart failure, increasing this type of drug (mainly when associated with cocaine) with secondary effects on the myocardium. Second, four cases of acute 
myocardial infarction in very young males $(15,17$, and 18 years $)$ in our series are noteworthy. These cases are associated with the lethal dose of ethyl alcohol $(4.4 \mathrm{~g} / \mathrm{L})$, phenytoin, trichloroethylene, and cocaine. However, this association (e.g., trichloroethylene and myocardial infarction or failure) still requires better explanations. It is not possible only with these data to establish a cause-and-effect relationship between them. In addition, drowning was associated with four deaths of adolescents with a positive toxicology for alcohol (4.1g/L; 2.3g/L; 1.3g/L; 0.7g/L, respectively). Thus, despite other possible explanations, it is essential to note that alcohol reduces the individual's reflexes and reaction capacity, facilitating accidents such as drowning. Acute hemorrhage (acute anemia) was described in four reports associated with blunt agent trauma and blood alcohol. In addition, two cases of hanging in boys were associated with a positive test for ethyl alcohol. In six reports, pulmonary causes related to death, pulmonary edema with or without pulmonary hemorrhage were described. Trichloroethylene was present in six cases, either alone or in association with other drugs. We also observed two lung disease cases, but one with a positive toxicology for phenytoin and another for a tricyclic antidepressant. A summary of all causes of death, according to age, sex, and positive toxicological examination, can be seen in Table 1.

Table 1: Distribution of the causes of death and the positivity of drug tests according to the age and sex of the victim.

\begin{tabular}{|c|c|c|c|}
\hline Age & Sex & Cause of Death & Toxicological \\
\hline 10 & M & Traumatic brain injury & Ethyl Alcohol (1,4g/L) \\
\hline 15 & M & Gunshot wound bleeding & Ethyl Alcohol (0,9g/L) \\
\hline 16 & $\mathrm{~F}$ & Traumatic brain injury & Ethyl Alcohol (3,0g/L) \\
\hline 16 & M & Traumatic internal bleeding (blunt trauma) & Ethyl Alcohol (2,0g/L) \\
\hline 16 & $\mathrm{~F}$ & Traumatic brain injury & Ethyl Alcohol (1,5g/L) \\
\hline 16 & M & Multiple blunt trauma & Ethyl Alcohol (2,5g/L) \\
\hline 17 & M & Drowning & Ethyl Alcohol (4,1g/L) \\
\hline 17 & M & Hanging & Ethyl Alcohol (0,8g/L) \\
\hline 17 & M & Gunshot wound bleeding & Ethyl Alcohol (1,9g/L) \\
\hline 17 & M & Traumatic brain injury & Ethyl Alcohol (3,4g/L) \\
\hline 17 & M & Multiple blunt trauma & Ethyl Alcohol (2,1g/L) \\
\hline 17 & M & Multiple blunt trauma & Ethyl Alcohol (4,4g/L) \\
\hline 17 & M & Drowning & Ethyl Alcohol (0,7g/L) \\
\hline 18 & M & Gunshot wound bleeding & Ethyl Alcohol (0,9g/L) \\
\hline 18 & M & Gunshot wound bleeding & Ethyl Alcohol (0,7g/L) \\
\hline 18 & M & Acute myocardial infarction & Ethyl Alcohol (4,4 g/L) \\
\hline 18 & M & Traumatic internal bleeding (blunt trauma) & Ethyl Alcohol (0,8g/L) \\
\hline 18 & M & Drowning & Ethyl Alcohol (2,3g/L) \\
\hline 18 & M & Drowning & Ethyl Alcohol (1,3g/L) \\
\hline 18 & M & Traumatic brain injury & Ethyl Alcohol (0,5g/L) \\
\hline 18 & M & Hanging & Ethyl Alcohol $(2,7 \mathrm{~g} / \mathrm{L})$ \\
\hline 18 & M & Exogenous intoxication & Ethyl Alcohol $(4,4 \mathrm{~g} / \mathrm{L})$ \\
\hline 15 & M & Acute myocardial infarction & Phenytoin \\
\hline 15 & M & Tuberculosis & Phenytoin \\
\hline 18 & M & Exogenous intoxication & Carbamazepine and cocaine $(276 \mathrm{ng} / \mathrm{mL})$ \\
\hline 18 & $\mathrm{~F}$ & Pneumonia & Tricyclic antidepressant \\
\hline 18 & M & Exogenous intoxication & Diazepam \\
\hline 14 & M & Exogenous intoxication & Trichloroethylene and chloroform \\
\hline 15 & M & Pulmonary edema & Trichloroethylene, phenytoin, and cocaine \\
\hline 15 & M & Pulmonary edema & $\begin{array}{l}\text { Trichloroethylene, ethyl alcohol }(1,2 \mathrm{~g} / \mathrm{L}) \\
\text { and cocaine }(133 \mathrm{ng} / \mathrm{mL})\end{array}$ \\
\hline 16 & M & Exogenous intoxication & Trichloroethylene \\
\hline 16 & M & Exogenous intoxication & Trichloroethylene \\
\hline 16 & $\mathrm{~F}$ & Pulmonary edema & Trichloroethylene \\
\hline
\end{tabular}




\begin{tabular}{|c|c|c|c|}
\hline 17 & M & Acute myocardial infarction & Trichloroethylene and THC (marijuana) \\
\hline 17 & M & Edema pulmonar & Trichloroethylene \\
\hline 17 & M & Exogenous intoxication & Trichloroethylene and chloroform \\
$(0,3 \mathrm{~g} / \mathrm{L})$
\end{tabular}

\section{Discussion}

All studies indicate alcohol as the drug most used by adolescents, followed at a distance by inhalants and psychotropic medication. In the final plan, illicit drugs, such as marijuana and cocaine appear [11]. Authorities routinely assume that teen abuse is heroin, cocaine, and other drugs. Such drugs cause more significant harm, but their use is infrequent among adolescents, compared to other substances, which are also harmful, such as tobacco, alcohol, and marijuana. It is essential to know that cocaine is used as "crack" smoked in some pipes. In the long run, smoking cigarettes is responsible for many illnesses and loss of years of life than all other drugs combined. Alcohol is involved in more than half of the deaths of young people in car accidents. Marijuana interferes with memory and learning [12]. Our study corroborates other studies already carried out on the topic involving drug use by children and adolescents. Although according to data from CEBRID/UNIFESP [7], the substance most frequently found in this population is ethyl alcohol, in $60 \%$ of cases, in our study, the rate of children and adolescents autopsied in Medicolegal Institute in the State of São Paulo in 2015, with positive examination toxicology for ethyl alcohol was above $50 \%$.

These data suggest that adolescents on the effect of psychoactive substances have impaired attention, judgment, and response capacity, making them easy victims of deaths from external causes. In addition, alcohol use during water activities dramatically increases the risk of drowning, for example [13]. In our series, we found four drowning cases, and all of them were associated with the use of ethyl alcohol. It is essential to point out that we found ethyl alcohol, as an isolated drug, in more than half of the cases analyzed.
This number is practically the same $50 \%$ reported of alcohol use by students in the United States [9]. Ethyl alcohol is, therefore, the psychoactive drug most frequently found in cases of violent deaths of children and adolescents who undergo toxicological examination at the IML of the State of São Paulo Among the adolescents, half had exogenous intoxication as the immediate cause of death, and two cases of pulmonary edema were attributed to the use of trichloroethylene. Trichloroethylene, a halogenated ethylene derivative used by adolescents by inhalation, can cause gastric symptoms (diarrhea, nausea, vomiting), narcosis and, depending on the amount, can cause pulmonary edema or fatal hepatic necrosis [14]. As pointed by Da Broi [15], "In the event of repeated cycles of inhalation, a dangerous and uncontrolled systemic accumulation of trichloroethylene may occur, followed by central nervous system depression, coma and lethal cardiorespiratory arrest [15].

"However, the association of this type of drug with cardiac failure is not well explained yet, and it requires further studies. Anyway, adolescents showed a high rate of alcohol consumption associated with violent deaths (drowning, head trauma, and gunshot wounds, among others), with this association being a public health problem. Mortality caused by alcohol can result from direct action by neurological disinhibition or impairment of cognition, functioning as a triggering factor for violence. A study published in 2001 estimated that alcohol dependence reached $20,910,000$ people in Brazil, representing 12.3\% of the population [16]. Our study showed that a 10 -year-old child was a victim of fatal violence due to head trauma and had an elevated serum alcohol concentration. According to data from the Ministry of Health of 2010, in Brazil, in 2007, alcohol consumption started at 14 and 17 
years (average of 13.9 years) [17]. Apparently, alcohol consumption in our country has reached younger children, which requires greater attention from health authorities. So, the data obtained in this study shows a worrying panorama. Therefore, the proposal is to continue this research by evaluating the deaths of children and adolescents in the following years.

\section{Conclusion}

The present study found a frequency of $46.82 \%$ of positive toxicological tests performed in children and adolescents who died from an external cause. The main substances found were ethyl alcohol and trichloroethylene in both sexes. In females, $37.5 \%$ of tests were positive for ethyl alcohol and $25 \%$ for trichloroethylene. Otherwise, we found $60 \%$ for ethyl alcohol, $8.75 \%$ for trichloroethylene, and $8.75 \%$ for cocaine in males. The mean age found was 16.5 years for males and 16.9 years for females. Of the deaths analyzed (47), all had a positive toxicological test. This association represents $91.48 \%$, obtained from $87.5 \%$ frequency in females and $92.3 \%$ in males.

\section{References}

1. (1998) Brasília: Secretariat of labor inspection, ministry of labor. Child and adolescent statute-ECA, Brazil.

2. (2017) Brazilian Institute of Geography and Statistics-IBGE, Brazil.

3. (2017) Mortality information system.

4. Pechansky F, Szobot CM, Scivoletto S (2004) Alcohol use among adolescents: Concepts, epidemiological characteristics and etiopathogenic factors. Rev Bras Psiquiatr 26(Supl I): 14-17.
6. France SGS (2016) Forensic medicine/genival veloso de France. $\left(10^{\text {th }}\right.$ ed). Rio de Janeiro: Guanabara Koogan, Brazil.

7. (2010) VI national survey on the consumption of psychotropic drugs among elementary and high school students from public and private teaching networks in the 27 Brazilian capitals.

8. Oliveira MLF, Arnauts I (2011) Alcohol intoxication in children and adolescents: Data from a toxicology assistance center Esc. Anna Nery 15(1): 83-89.

9. Rozin L, Zagone IPS (2012) Risk factors for alcohol dependence in adolescents. Minutes Paul Enferm 25(2): 314-318.

10. Cesar BAL (2006) Female alcoholism: A study of its peculiarities. preliminary results. J Bras Psiquiatr 55(3): 208-211.

11. Sinagawa DM, Godoy CD, Carvalho Ponce J, Andreuccetti G, Carvalho DG, et al. (2008) Alcohol use by victims of violent death in the State of São Paulo. Health Ethics Justice 13(2): 65-71.

12. Silber TJ, Souza RPD (1981) Drug use and abuse in adolescence: What to know and what to do. Adolescence Latinoam 3: 148-162.

13. Mott TF, Lattimer KM (2021) Prevention and treatment of drowning. American Family Physician 93(7): 576-582.

14. Prat S, Reig R, Borrá L, Corbella J (1988) Trichlorethylene poisoning. Presentation of three cases and review of the literature. Rev Med Univ Navarre 32(4): 204-207.

15. Da Broi U, Colatutto A, Room P, Desinan L (2015) Medico legal investigations into sudden sniffing deaths linked with trichloroethylene. J Forensic Leg Med 34: 81-87.

16. Carlini EA, Galduroz JCF, Noto AR, Nappo SA (2001) Household survey of psychotropic drugs in Brazil: Study involving the 107 largest cities in the country-2001. São Paulo: Cebrid/Unifesp, Brazil.

17. (2010) Ministry of health. National guidelines for comprehensive health care for adolescents and youth in the promotion, protection and recovery of health, Brazil, pp.41

5. (2017) Education portal. Drug addiction. 